\title{
CREB regulates spine density of lateral amygdala neurons: implications for memory allocation
}

\author{
Derya Sargin ${ }^{1,2,3,4}$, Valentina Mercaldo ${ }^{1,2,3,4}$, Adelaide P. Yiu ${ }^{1,2,3,4}$, Gemma Higgs ${ }^{1,2,3,4}$, Jin-Hee Han ${ }^{1,2,3,4,5}$, \\ Paul W. Frankland ${ }^{1,2,3,4}$ and Sheena A. Josselyn ${ }^{1,2,3,4 *}$ \\ 1 Program in Neurosciences and Mental Health, Hospital for Sick Children, Toronto, ON, Canada \\ ${ }^{2}$ Department of Psychology, University of Toronto, Toronto, ON, Canada \\ ${ }^{3}$ Department of Physiology, University of Toronto, Toronto, ON, Canada \\ ${ }^{4}$ Institute of Medical Science, University of Toronto, Toronto, ON, Canada \\ ${ }^{5}$ Laboratory of Neural Circuit and Behavior, Department of Biological Sciences, KAIST Institute for the BioCentury, Korea Advanced Institute of Science and \\ Technology, Daejeon, Korea
}

\section{Edited by:}

Jonathan E. Ploski, University of Texas at Dallas, USA

Reviewed by:

Tsuyoshi Miyakawa, Fujita Health University, Japan

Marie H. Monfils, University of

Texas at Austin, USA

*Correspondence:

Sheena A. Josselyn, Program in Neurosciences and Mental Health, The Hospital for Sick Children, 555 University Ave, Toronto, ON M5G $1 \times 8$, Canada

e-mail: sheena.josselyn@sickkids.ca
Neurons may compete against one another for integration into a memory trace. Specifically, neurons in the lateral nucleus of the amygdala with relatively higher levels of cAMP Responsive Element Binding Protein (CREB) seem to be preferentially allocated to a fear memory trace, while neurons with relatively decreased CREB function seem to be excluded from a fear memory trace. CREB is a ubiquitous transcription factor that modulates many diverse cellular processes, raising the question as to which of these CREB-mediated processes underlie memory allocation. CREB is implicated in modulating dendritic spine number and morphology. As dendritic spines are intimately involved in memory formation, we investigated whether manipulations of CREB function alter spine number or morphology of neurons at the time of fear conditioning. We used viral vectors to manipulate CREB function in the lateral amygdala (LA) principal neurons in mice maintained in their homecages. At the time that fear conditioning normally occurs, we observed that neurons with high levels of CREB had more dendritic spines, while neurons with low CREB function had relatively fewer spines compared to control neurons. These results suggest that the modulation of spine density provides a potential mechanism for preferential allocation of a subset of neurons to the memory trace.

Keywords: CREB, amygdala, fear memory, dendritic spines, viral vector

\section{INTRODUCTION}

The cAMP Responsive Element Binding Protein (CREB) is an activity regulated transcription factor that modulates the transcription of genes with cAMP responsive elements (CRE) located in their promoter regions. Early research in Aplysia (Dash et al., 1990; Kaang et al., 1993; Bartsch et al., 1995) and D. melanogaster (Yin et al., 1994, 1995; Perazzona et al., 2004) first implicated CREB in memory formation. Since that time, the important role of CREB in memory has been shown across a variety of species from C. elegans (Kauffman et al., 2010; Lau et al., 2013) to rats (Guzowski and McGaugh, 1997; Josselyn et al., 2001), mice (Bourtchuladze et al., 1994; Kida et al., 2002; Pittenger et al., 2002; Gruart et al., 2012) and humans (Harum et al., 2001) (for review, see Josselyn and Nguyen, 2005) but see Balschun et al. (2003). For instance, we (Han et al., 2007), and others (Zhou et al., 2009; Rexach et al., 2012) previously showed that increasing CREB function in a small portion of lateral amygdala (LA) neurons (roughly $8-10 \%$ of LA principal neurons) was sufficient to enhance auditory fear memory. Moreover, we observed that LA neurons with relatively higher CREB function at the time of training were preferentially included, whereas neurons with lower CREB function were excluded, from the subsequent LA fear memory trace (Han et al., 2007, 2009). Conversely, disrupting CREB function by expressing a dominant negative version of
CREB $\left(\mathrm{CREB}^{\mathrm{S} 133 \mathrm{~A}}\right)$ in a similar small percentage of LA neurons did not affect auditory fear memory, likely because the neurons expressing $\mathrm{CREB}^{\mathrm{S} 133 \mathrm{~A}}$ were largely excluded from the memory trace. Furthermore, post-training ablation (Han et al., 2009) or silencing (Zhou et al., 2009) of neurons overexpressing CREB disrupted subsequent expression of the fear memory, confirming the importance of these neurons. Together, these data suggest that neurons with high levels of CREB at the time of training are preferentially allocated to the memory trace because they somehow outcompete their neighbors (Won and Silva, 2008).

CREB is a ubiquitous transcription factor implicated in many diverse cellular processes in addition to memory formation, including regulation of proliferation, survival, apoptosis, differentiation, metabolism, glucose homeostasis, spine density, and morphology (Bourtchuladze et al., 1994; Murphy and Segal, 1997; Silva et al., 1998; Mayr and Montminy, 2001; Lonze et al., 2002; Wayman et al., 2006; Aguado et al., 2009; Altarejos and Montminy, 2011). Which of these CREB-mediated processes is/are important for memory allocation? Here we investigated one CREB-mediated process, the regulation of spine density and morphology.

Dendritic spines are small, highly motile structures on dendritic shafts which provide flexibility to neuronal networks. As an increase in the synaptic strength between neurons is thought 
to underlie memory formation (Bailey and Kandel, 1993; Bailey et al., 1996) and the majority of excitatory synapses occur on dendritic spines (Harris and Stevens, 1988, 1989; Farb et al., 1992), it has long been thought that dendritic spines serve as storage sites for synaptic strength, an idea first proposed by Santiago Ramón y Cajal over 100 years ago (Cajal, 1995). In this way, the growth and re-structuring of dendritic spines is thought to be crucial for memory formation.

A role for CREB in spine formation was first reported by Murphy and Segal (1997) who showed that estradiol treatment increased both levels of activated (phosphorylated) CREB and spine density in cultured hippocampal neurons. CREB was subsequently shown to regulate spine morphology in hippocampal neurons both in organotypic culture (Impey et al., 2010) and in vivo (Marie et al., 2005), as well as in visual cortex principal neurons (Suzuki et al., 2007). The new spines formed following overexpression of CREB may contain silent synapses (NMDA receptors only), suggesting that they may be "primed" for incorporation into future memory circuits (Marie et al., 2005). Consistent with this, increasing CREB function in hippocampal CA1 principal neurons was sufficient to restore both the decrease in spine density and spatial memory in a mouse model of Alzheimer's disease (Yiu et al., 2011).

We previously reported that neurons with increased CREB at the time of training are selectively allocated to a fear memory trace and a variety of evidence shows that increasing CREB function increases spine density. Therefore, we investigated whether neurons with increased CREB at the time of training also have an increase in dendritic spine density, thereby providing a potential mechanism of the preferential allocation of these neurons to the memory trace.

\section{MATERIALS AND METHODS MICE}

Adult male F1 hybrid (C57 BL/6NTac $\times 129$ S6/SvEvTac) mice were used for all experiments. This genetic background has been used extensively in behavioral studies and are well characterized (Silva et al., 1997). Mice were group housed (2-5 mice per cage) on a $12 \mathrm{~h}$ light/dark cycle and provided with food and water ad libitum. All experimental procedures were conducted in accordance with the guidelines of the Canadian Council on Animal Care (CCAC) and the National Institutes of Health (NIH) and approved by the Animal Care Committee at the Hospital for Sick Children.

\section{HSV VECTORS}

Neurotropic replication-defective herpes simplex viral (HSV) vectors were used to manipulate CREB function in individual LA principal neurons. Wild-type or dominant negative $\mathrm{CREB}^{\mathrm{S} 133 \mathrm{~A}}$ cDNAs were cloned into the HSV amplicon under the control of the constitutive promoter for the HSV immediate early gene IE4/5. These vectors co-expressed GFP which was driven by CMV promoter [HSV-p1005; Russo et al., 2009]. In this vector therefore, the GFP protein is not fused to CREB and may thus fill the infected cell. As a control, we used HSV vector expressing GFP alone. HSV virus was packaged using a replication-defective helper virus as previously described (Josselyn et al., 2001; Barrot et al., 2002; Carlezon and Neve, 2003; Han et al., 2008;
Vetere et al., 2011; Cole et al., 2012). Virus was purified on a sucrose gradient, pelleted and resuspended in $10 \%$ sucrose. The average titer of the virus stocks was typically $4.0 \times 10^{7}$ infectious units/ml.

\section{SURGERY}

Mice were pretreated with atropine sulfate $(0.1 \mathrm{mg} / \mathrm{kg}$, i.p.), anesthetized with chloral hydrate $(400 \mathrm{mg} / \mathrm{kg}$, i.p.) and placed in a stereotaxic frame. Skin was retracted and holes were drilled in the skull above the LA (anteroposterior $=-1.4$, mediolateral $= \pm 3.4$, ventral $=-5.0 \mathrm{~mm}$ from bregma) according to (Paxinos and Franklin, 2001). Viral vector was microinjected through glass micropipettes connected via polyethylene tubing to a microsyringe (Hamilton, Reno, NV) at a rate of $0.1 \mu \mathrm{l} / \mathrm{min}$. Micropipettes were left in place an additional $10 \mathrm{~min}$ following microinjection to ensure diffusion of vector. For behavior analysis, a volume of $1.5 \mu \mathrm{l}$ and for spine analysis, a volume of $1.0 \mu \mathrm{l}$ was microinjected bilaterally at a rate of $0.1 \mu \mathrm{l} / \mathrm{min}$. Micropipettes were slowly retracted, the incision site closed and mice were treated with analgesic (ketoprofen, $5 \mathrm{mg} / \mathrm{kg}$, s.c.). Three $\mathrm{d}$ following surgery, at a maximal transgene expression for HSV vector system (Josselyn et al., 2001; Barrot et al., 2002; Vetere et al., 2011; Cole et al., 2012), mice were either fear conditioned or perfused for dendritic spine analysis.

\section{AUDITORY (TONE) FEAR CONDITIONING}

During training, mice were placed in a Med Associates (St. Albans, VT) Plexiglas and metal chamber $(24 \times 30 \times 21 \mathrm{~cm}$, context A; Cxt A) located in a soundproof room. After $2 \mathrm{~min}$, a tone $(2800 \mathrm{~Hz}, 30 \mathrm{~s}, 85 \mathrm{~dB})$ that co-terminated with a footshock $(2 \mathrm{~s}$, $0.4 \mathrm{~mA}$ ) was presented. Mice remained in the chamber for an additional $30 \mathrm{~s}$ and then returned to the homecage. Testing for auditory fear memory occurred $24 \mathrm{~h}$ later by placing mice in a novel context (context B; Cxt B) and 2 min later, presenting the tone previously paired with footshock for $3 \mathrm{~min}$. The percentage of time mice spent freezing (the cessation of all movement except respiration) before and during the tone was measured using an automated system (Actimetrics) and was used as our index of memory. Immediately after testing, mice were deeply anesthetized and perfused.

\section{IMMUNOHISTOCHEMISTRY}

To visualize the number and morphology of dendritic spines in the neurons we infected, we took advantage of the GFP expressed by all viral vectors. We amplified the GFP signal using an antibody directed against GFP. $72 \mathrm{~h}$ after surgery, mice were deeply anesthetized using chloral hydrate $(400 \mathrm{mg} / \mathrm{kg}$, i.p.) and transcardially perfused with $0.1 \mathrm{M}$ PBS followed by $4 \%$ paraformaldehyde (PFA). Brains were post-fixed overnight in $4 \%$ PFA and transferred to $30 \%$ sucrose for cryoprotection. Coronal $(50 \mu \mathrm{m})$ sections were prepared and immunohistochemistry for GFP was performed. Free-floating sections were incubated in blocking solution ( $0.1 \%$ BSA, $5 \%$ NGS, $0.2 \%$ Triton-X-100 in $0.1 \mathrm{M}$ PBS) for $1 \mathrm{~h}$ and labeled with anti-GFP rabbit polyclonal antibody (1:500, Invitrogen) overnight at $4^{\circ} \mathrm{C}$. Following PBS washes, sections were incubated with goat anti-rabbit Alexa 488 (1:500, Invitrogen) for $2 \mathrm{~h}$ at room temperature. Sections were washed 
with PBS, mounted on gelatin-coated slides and coverslipped using Vectashield Hardmount with DAPI (Vector Laboratories).

\section{CONFOCAL ANALYSIS}

GFP-positive LA neurons (neurons infected by viral vectors) were first identified using a 10x objective (LSM 710, Zeiss). Infected neurons were included in the subsequent spine analysis if (i) cell body was not damaged; (ii) dendritic projections remained within the LA; (iii) neurons could clearly be identified without interference from neighboring infected cells; (iv) neurons had first, second, and third order branches. Fourth order branches were not included in the analysis as they often appeared truncated in our $50 \mu \mathrm{m}$ sections. Selected GFP-positive neurons were imaged using a 100x oil-immersion objective. $Z$ series were obtained by imaging serial confocal planes at $0.25 \mu \mathrm{m}$ intervals. Dendrites and spines were traced manually from the image stacks using Neurolucida software and analyzed with Neurolucida Explorer (MBF version 9).

\section{Dendritic morphology}

Image analysis was performed by two researchers unaware of the treatment condition of the mouse. Dendrites were traced. The first dendritic process emanating from the cell body was defined as the primary (first order) branch. Subsequent branches that bifurcated from the first branch order were designated as second order branches, and so forth. Truncated branches or those that did not remain within the image window were excluded from subsequent analysis.

\section{Spine morphology}

Dendritic spines were defined as small protrusions connected to the dendritic shaft (Feldman and Dowd, 1975). Spines show a distinct morphology and vary in length from $0.5-4 \mu \mathrm{m}$ (Peters and Kaiserman-Abramof, 1970; Horner and Arbuthnott, 1991). Therefore, we analyzed all dendritic protrusions that were less than or equal to $4 \mu \mathrm{m}$ in length (Horner and Arbuthnott, 1991). Because this method has been shown to produce reliable results (Horner and Arbuthnott, 1991), no attempt was made to introduce a correction factor for hidden spines. Spines were counted and spine density was calculated as the number of spines on a branch divided by the length of the branch. Spine length was defined as the distance between the spine tip and the base of the spine. Spine head diameter was identified as the maximum width of the spine head (see Figure 2B).

\section{STATISTICAL ANALYSIS}

Data were analyzed with 1 or 2-Way analyses of variance (ANOVAs) using Statistica (Statsoft) software. For the auditory fear conditioning data, we analyzed the percentage of time spent freezing to before $(2 \mathrm{~min})$ and during $(3 \mathrm{~min})$ the tone. For dendritic and spine morphological analysis, data were first averaged by branch order per cell, then by animal and finally by vector group (GFP, CREB, or CREB ${ }^{\mathrm{S} 133 \mathrm{~A}}$ ). Newman-Keuls post-hoc tests were performed where appropriate. To protect against potential type 1 errors resulting from multiple comparisons of 5 different measures of neuronal morphology (i.e., spine density, spine length, spine head diameter, dendrite length, and dendrite volume), we also performed a Bonferroni correction (corrected $\alpha=0.01)$. All significant main effects remained significant after correction.

\section{RESULTS}

INCREASING CREB IN A SMALL PORTION OF LA NEURONS ENHANCES MEMORY FORMATION WHILE EXPRESSING THE DOMINANT NEGATIVE VERSION OF CREB HAS NO EFFECT

We first confirmed the effects of manipulating CREB function in a small portion $(\sim 8-10 \%)$ of LA neurons on the formation of tone fear memory by microinjecting HSV vectors encoding GFP, CREB or dominant-negative CREB ( $\left.\mathrm{CREB}^{\mathrm{S} 133 \mathrm{~A}}\right)$ into the LA of adult mice $3 \mathrm{~d}$ before fear conditioning (see Figure 1A). During training (Cxt A), mice received a single tone (conditioned stimulus, CS) footshock (0.4 mA) (US) pairing that did not induce ceiling levels of freezing. Tone fear memory was assessed $24 \mathrm{~h}$ after training. Mice were placed in a novel context (Cxt B) and $2 \mathrm{~min}$ later the tone was presented for $3 \mathrm{~min}$ (Figure 1B). Consistent with our earlier findings (Han et al., 2007, 2009) and those of other research groups (Zhou et al., 2009; Rexach et al., 2012), increasing CREB levels in a small portion of LA neurons enhanced tone fear memory, while disrupting CREB function by microinjecting $\mathrm{CREB}^{\mathrm{S} 133 \mathrm{~A}}$ vector had no effect on fear memory (Figures 1C,D). These results were supported by a Vector (GFP, CREB, CREB ${ }^{\text {S133A }}$ vector $) \times$ Time $(5 \mathrm{~min})$ ANOVA showing significant main effects of Vector $\left[F_{(2,28)}=6.8, p=0.004\right]$ and Time $\left[F_{(4,112)}=16.5, p \leq 0.0001\right]$ but no Vector $\times$ Time interaction $\left[F_{(8,112)}=6.8, p=0.32\right]$. A subsequent One-Way ANOVA performed on freezing during the entire CS presentation showed a significant effect of Vector $\left[F_{(2,28)}=7.1, p=0.003\right]$, as mice microinjected with CREB vector froze significantly more than mice with GFP $(p=0.006)$ or $\mathrm{CREB}^{\mathrm{S} 133 \mathrm{~A}}$ vector $(p=0.004)$, which did not differ from each other $(p=0.83)$ (Newman-Keuls post-hoc) (Figure 1D). Importantly, when first placed in Cxt B, mice generally showed little freezing before the tone was presented and baseline levels of freezing in CREB or CREB ${ }^{\text {S133A }}$ groups did not differ from the GFP group $(p=0.18, p=0.19$ respectively). We next examined a possible mechanism underlying this preferential recruitment to the memory trace.

\section{CREB MODULATES DENDRITIC SPINE DENSITY OF LA NEURONS}

CREB is a ubiquitous transcription factor that has been implicated in many cellular processes, including regulating dendritic spine density. We hypothesized that neurons may be recruited to the memory trace based on their relative spine density, and examined whether neurons infected with CREB vector show greater dendritic spine density at the time of training than neurons infected with $\mathrm{CREB}^{\mathrm{S} 133 \mathrm{~A}}$ or Control GFP vector. We microinjected a separate co-hort of mice with GFP, CREB, or CREB ${ }^{\text {S133A }}$ vector as above but did not train these mice. Instead, $72 \mathrm{~h}$ following surgery (at a time when they would have received auditory fear conditioning) we removed their brains and examined spine density (Figure 2A).

There are two major neuronal cell populations in LA: pyramidal glutamatergic projection neurons and local circuit $\gamma$-aminobutyric acid (GABA)-ergic interneurons (McDonald, 1984). Glutamatergic pyramidal-like principal neurons comprise the majority (85-90\%) (McDonald, 1992; Sah et al., 2003) and 


\section{A}
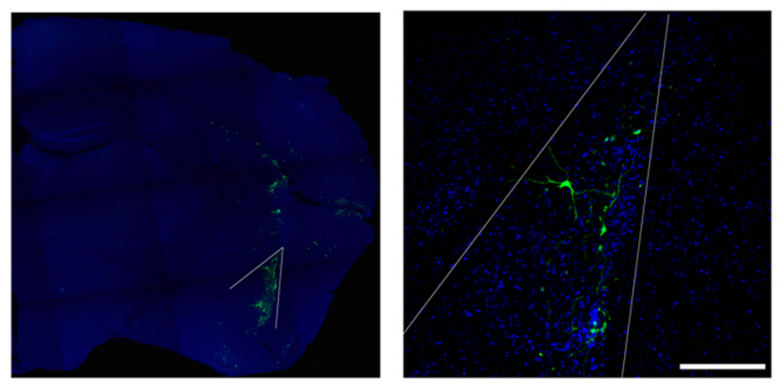

B
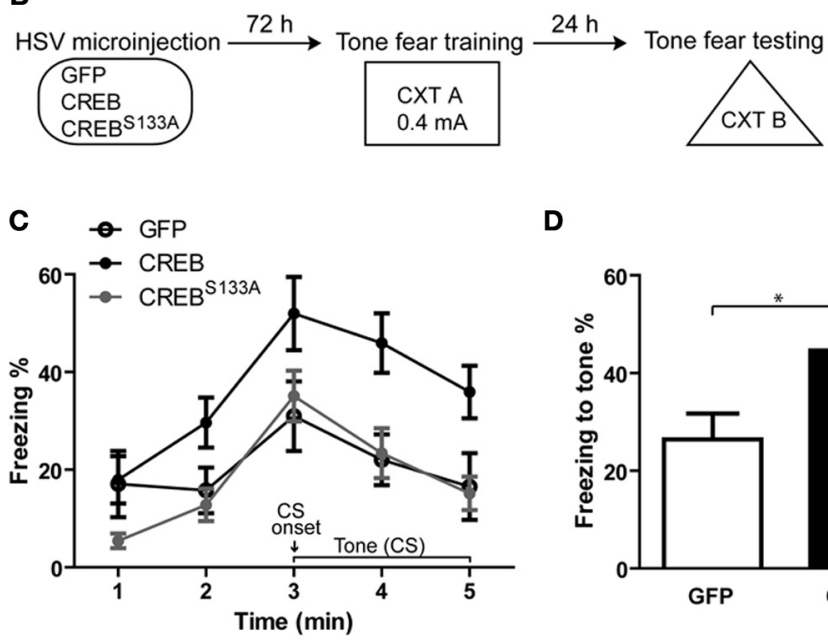

D

FIGURE 1 | Overexpressing CREB in LA neurons enhances, while dominant negative CREB $^{\text {S133A }}$ does not affect, auditory fear memory.

(A) Visualizing neurons infected with viral vectors. Left: Outline of the LA. Maximum intensity projection is shown. Right: LA principal neurons expressing GFP $72 \mathrm{~h}$ following viral vector microinjection (nuclei stained with DAPI, infected neurons visualized with anti-GFP antibody). $0.25 \mu \mathrm{m}$ optical section is shown. Scale bar, $100 \mu \mathrm{m}$. (B) Experimental design. Auditory (tone) fear conditioning was conducted $72 \mathrm{~h}$ after HSV microinjection. Mice were placed in

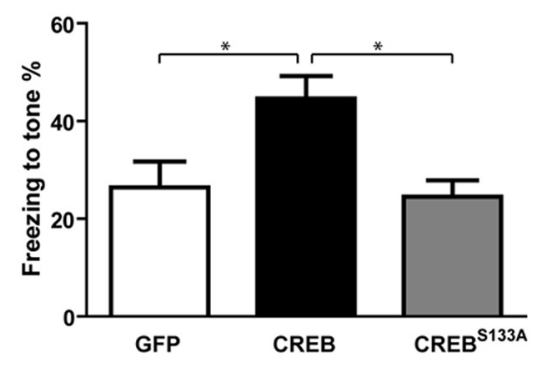

can be visually identified according to the shape of their somata. Thus, we identified infected neurons as LA principal neurons based on their pyramidal shaped somata. In mice microinjected with CREB vector, infected neurons showed higher spine density compared to infected neurons in mice microinjected with Control (GFP-only) vector. In contrast, $\mathrm{CREB}^{\mathrm{S} 133 \mathrm{~A}}$-infected neurons showed lower spine density than control neurons. This pattern of results was observed across branch order (Figures 2C,D). A Vector (GFP, CREB, CREB ${ }^{\mathrm{S} 133 \mathrm{~A}}$ ) by Branch order (3) repeated-measures ANOVA showed significant main effects of Vector $\left[F_{(2,15)}=16.8\right.$, $p \leq 0.0001]$ and Branch order $\left[F_{(2,30)}=37.2, p \leq 0.0001\right]$ but no significant interaction between Vector $\times$ Branch order $\left[F_{(4,30)}=\right.$ $0.2, p=0.90]$. Post-hoc Newman-Keuls analysis on the significant main effects revealed that neurons with CREB vector had significantly greater spine density across branch orders compared to neurons infected with GFP $(p=0.02)$ or $\mathrm{CREB}^{\mathrm{S} 133 \mathrm{~A}}(p=0.0002)$ vectors (Figures 2C,E), while neurons with $\mathrm{CREB}^{\mathrm{S133A}}$ vector had lower spine density across branches relative to those expressing GFP only ( $p=0.004$ ) (Figures 2C,E). It is important to note that these changes in spine density occurred even though all mice were maintained in the homecage (and therefore, these changes in spine density cannot be attributed to fear conditioning).

Importantly, dendritic length per branch (Figure 3A) or total dendritic length did not appear to differ between vectors (Figure 3B). This observation was supported by repeated measures ANOVA showing no significant effect of Vector $\left[F_{(2,15)}=2.8, p=0.09\right]$ or interaction of Vector $\times$ Branch order $\left[F_{(4,30)}=0.7, p=0.60\right]$, but a significant main effect of Branch order $\left[F_{(2,30)}=10.9, p=0.0003\right]$. Therefore, dendritic length increased with increasing branch order, but this was not changed by CREB manipulation (Figures 3A,B). We also observed no difference in dendritic volume between neurons infected with the various vectors (Figures 3C,D). An ANOVA revealed no significant effects of Vector $\left[F_{(2,15)}=1.3, p=0.29\right]$, Branch order $\left[F_{(2,30)}=1.0, p=0.37\right]$ or Vector $\times$ Branch order interaction $\left[F_{(4,30)}=1.9, p=0.13\right]$. Therefore, manipulations of CREB function changed dendritic spine density without changing dendritic morphology. 


\section{A HSV microinjection $\stackrel{72 \mathrm{~h}}{\longrightarrow}$ Morphological analysis

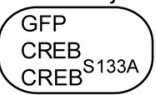

B
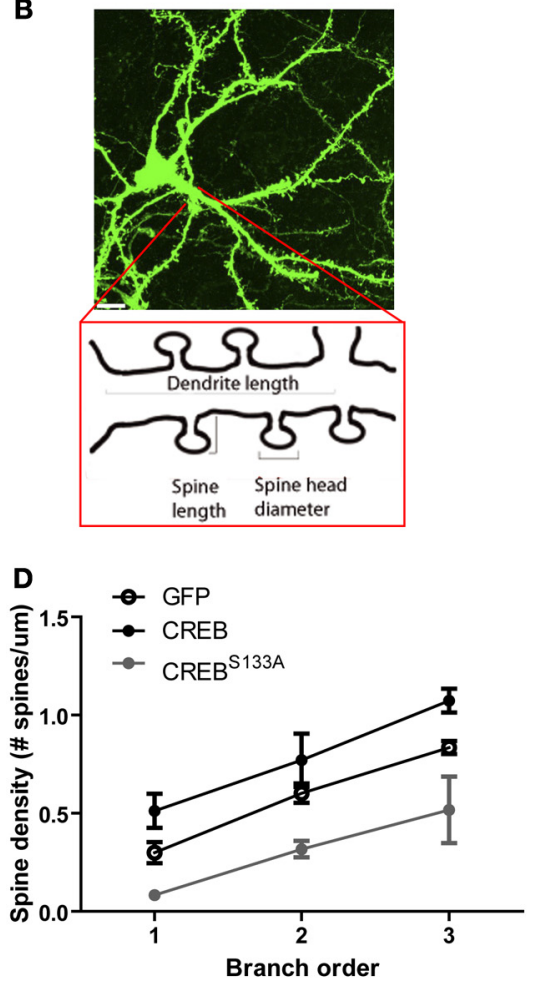

FIGURE 2 | CREB modulates dendritic spine density in LA neurons. (A) Experimental design. The morphology of infected LA neurons was analyzed $72 \mathrm{~h}$ after mice were microinjected with GFP, CREB or, CREB ${ }^{S 133 A}$ vectors (at the same time-point as training occurred in

Figure 1). Mice remained in the homecage after microinjection and were not fear conditioned. (B) Schematic representation of a dendritic segment showing the parameters analyzed (dendrite length, spine length, spine
C
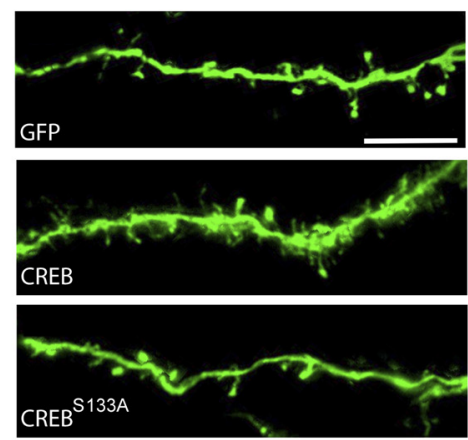

E

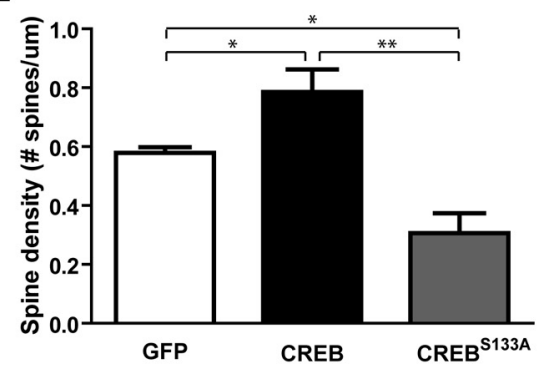

head diameter and spine density). Scale bar, $10 \mu \mathrm{m}$. (C) Representative dendritic segments of LA neurons from mice microinjected with GFP, $\mathrm{CREB}$, or $\mathrm{CREB}^{\mathrm{S} 133 \mathrm{~A}}$ vector. Scale bar, $5 \mu \mathrm{m}$. (D) Dendritic spine density shown at each branch order and (E) across all branches is increased in neurons with CREB vector $(n=6)$ and decreased in neurons with $\mathrm{CREB}^{\mathrm{S} 133 \mathrm{~A}}$ vector $(n=5)$ when compared to neurons with GFP vector $(n=7)$. Data represent mean \pm s.e.m. ${ }^{*} p<0.05$. ${ }^{* *} p<0.001$.

\section{SPINE MORPHOLOGY IS NOT ALTERED BY CREB OR CREBS133A EXPRESSION}

Alterations in spine morphology have been correlated with changes in spine function (Matsuzaki et al., 2001, 2004) and increasing CREB may induce formation of silent synapses (Marie et al., 2005). Spines with large bulbous heads are thought to contain large post-synaptic densities (PSD) (Harris et al., 1992) whereas spines with small heads and long necks may contain silent synapses (Matsuzaki et al., 2001, 2004). Prompted by these observations, we analyzed whether manipulations of CREB function altered spine morphology in mice maintained in the homecage by measuring spine length and head diameter (see Figure 2B). Interestingly, spine length, regardless of vector, increased slightly with increasing branch order \{Figures 4A,B; ANOVA showing no significant main effect of Vector $\left[F_{(2,15)}=\right.$ $0.8, p=0.45]$ or Vector $\times$ Branch order interaction $\left[F_{(4,30)}=\right.$ $0.6, p=0.63]$, but a significant main effect of Branch order $\left.\left[F_{(2,30)}=8.9, p=0.0009\right]\right\}$. We next examined whether CREB manipulation influenced spine head diameter (widest distance of the spine head, see Figure 2B). We observed no difference between spine head diameter between vectors, but a small change per branch order across all vectors \{Figures 4C,D no significant effect of Vector $\left[F_{(2,15)}=0.7, p=0.50\right]$ or Vector $\times$ Branch order interaction $\left[F_{(4,30)}=1.0, p=0.41\right]$ but a significant main effect of Branch order $\left.\left[F_{(2,30)}=4.2, p=0.02\right]\right\}$. Therefore, although CREB manipulations produced changes in dendritic spine density, these were not accompanied by changes in dendrite or overall spine morphology.

\section{DISCUSSION}

Previously, we and others observed that neurons with relatively increased CREB function at the time of training seem to be competitively advantaged over neighboring neurons for allocation to a fear memory trace. Here we examined whether an increase in spine density at the time of training might mediate this competitive advantage. To this end, we examined the effects of manipulating CREB function on dendritic spine density at the time of training. We found that in mice taken directly from the homecage, 

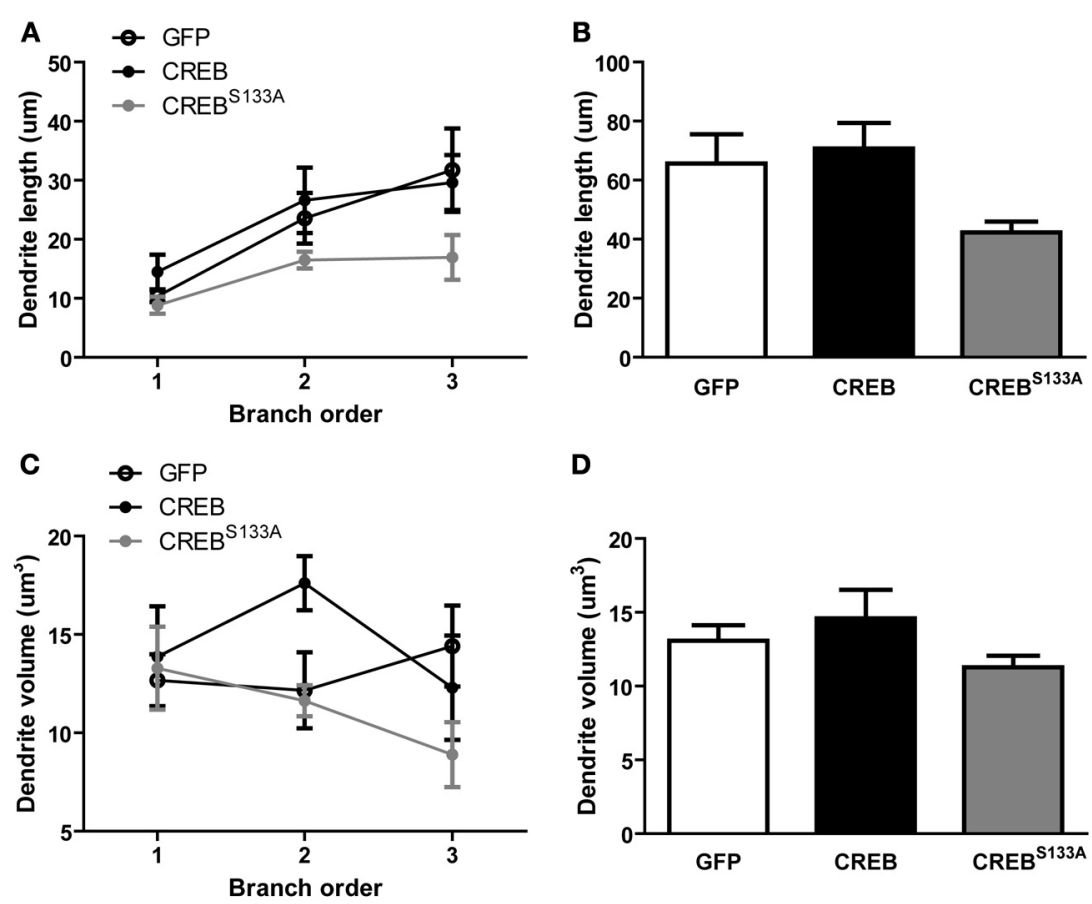

D

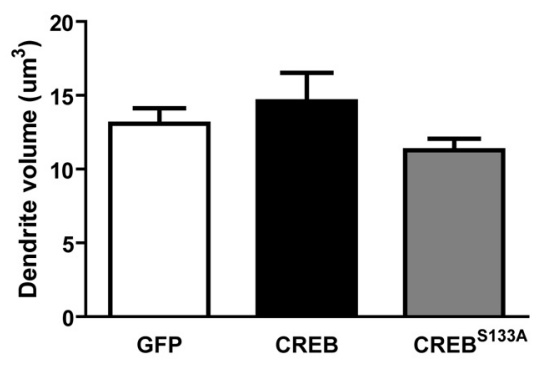

FIGURE 3 | CREB does not affect dendritic length and volume. (A)

Dendritic length per branch order and (B) across all branches was comparable between LA neurons overexpressing GFP $(n=7)$, CREB $(n=6)$, or

CREB $^{\mathrm{S133A}}$ ( $n=5$ ) vectors. (C) Dendrite volume per branch order and (D) across all branches did not differ between LA neurons overexpressing GFP $(n=7)$, CREB $(n=6)$, or CREB ${ }^{\mathrm{S} 133 \mathrm{~A}}(n=5)$ vectors.
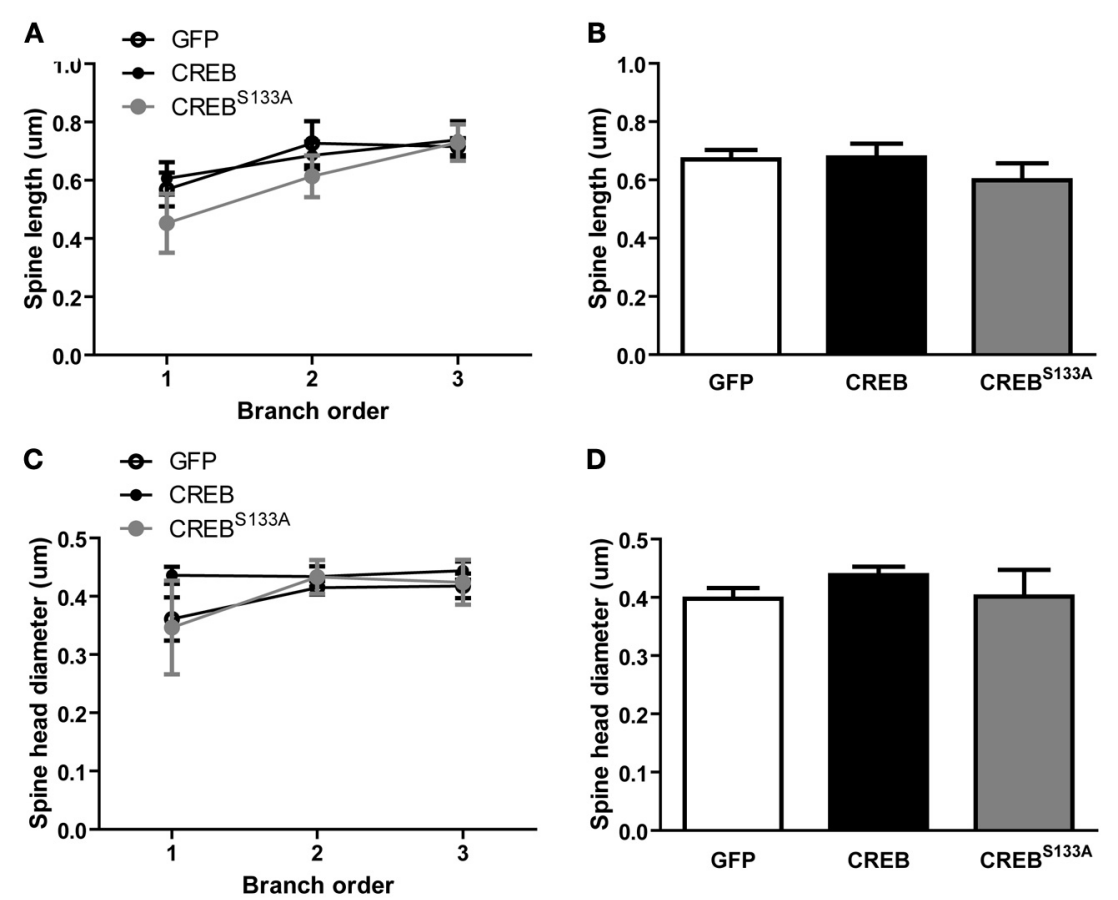

D

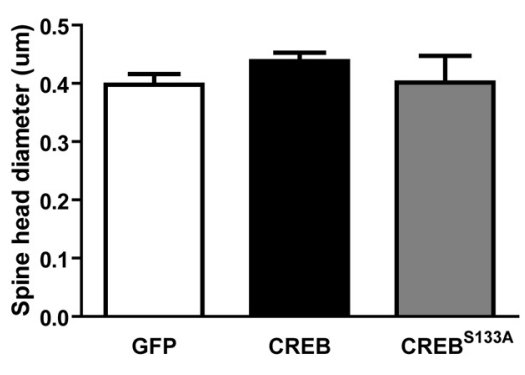

FIGURE 4 | CREB does not affect spine morphology. (A) Spine length at each branch order and (B) across all branches was similar between $L A$ neurons with $\operatorname{GFP}(n=7)$, CREB $(n=6)$, or $\operatorname{CREB}^{\mathrm{S} 133 \mathrm{~A}}(n=5)$ vectors. (C)

Spine head diameter at each branch order and (D) across all branches did not differ between LA neurons with GFP $(n=7)$, CREB $(n=6)$, or CREB ${ }^{\text {S133A }}$ $(n=5)$ vectors. 
neurons with CREB overexpression showed higher, while neurons with $\mathrm{CREB}^{\mathrm{S133A}}$ showed lower spine density, than control infected neurons. These data are consistent with the notion that one factor that may determine neuronal allocation for memory formation is relative spine density.

The LA is a key brain region important in mediating fear and anxiety (Davis, 1992) and some studies implicate CREB in "emotional" behavior (Barrot et al., 2002; Pandey et al., 2003). It is possible, therefore, that CREB overexpression in a small population of LA neurons leads to a general increase in fear and/or anxiety. Disruption of CREB function either generally in the brain (Valverde et al., 2004) or specifically in the amygdala (Pandey et al., 2005) has been reported to increase anxiety-like behavior in mice. On the other hand, local CREB overexpression has been shown to enhance excitability of LA neurons without causing alterations in anxiety or locomotor activity (Viosca et al., 2009). In our experiments, before the presentation of the tone (pre-CS), freezing levels of mice overexpressing $\mathrm{CREB}$ or $\mathrm{CREB}^{\mathrm{S133A}}$ did not differ from those overexpressing GFP. This ruled out the possibility that $\mathrm{CREB}$ or $\mathrm{CREB}^{\mathrm{S} 133 \mathrm{~A}}$ might lead to alterations in general fear and anxiety.

Studies in the 1990s first implicated CREB in the formation of long-term memory (LTM) (Dash et al., 1990; Yin et al., 1994, 1995). Building on these important findings, we (Josselyn and Nguyen, 2005; Han et al., 2007, 2009; Cole et al., 2012), and others (Bourtchuladze et al., 1994; Kida et al., 2002) (Viosca et al., 2009; Zhou et al., 2009; Rexach et al., 2012), showed that decreasing CREB function disrupts, while increasing CREB function enhances the formation of many types of memory in mammals [but see Balschun et al. (2003)]. The role of CREB in fear memory has been extensively studied in rodents. Mice lacking $\alpha$ and $\delta$ isoforms of CREB $\left(\mathrm{CREB}^{\alpha \delta}\right)$ showed impaired in LTM for both context and tone fear memories (Bourtchuladze et al., 1994). Similarly, CREB ${ }^{\text {comp }}$ mice, carrying one allele for the $\beta$ isoform of CREB, showed deficits in LTM for context and tone fear memories (Gass et al., 1998). CREB $^{\mathrm{IR}}$ mice which express $\mathrm{CREB}^{\mathrm{S133A}}$ in a temporally regulated manner have impaired context and tone fear memory following repression of CREB activity before training (Kida et al., 2002). Viral delivery of CREB into the amygdala using HSV enhanced LTM induced by massed training protocol in the fear potentiated startle paradigm in rats (Josselyn et al., 2001). CREB is thought to activate the transcription of target genes which ultimately serve as the building blocks for increasing the synaptic connections between neurons important for memory formation (Bartsch et al., 1998). It is interesting to note that CREB has also been implicated in human memory (Harum et al., 2001) and several human cognitive/memory disorders are linked to disruptions in the CREB signaling pathway (Josselyn and Nguyen, 2005). Together these data converge to indicate that CREB is critical for memory formation.

Previous studies have also established a possible role of CREB in maintaining spine number and morphology. Estradiol treatment in cultured hippocampal neurons led to increased phosphorylation of CREB which correlated with spinogenesis (Murphy and Segal, 1997). Enhancing CREB function upon expression of a constitutively active form of CREB (caCREB) in the CA1 region of hippocampus increased spine density in hippocampal neurons in vivo (Marie et al., 2005). CREB was also shown to regulate spine morphology in pyramidal neurons of the visual cortex (Suzuki et al., 2007). Expression of caCREB in organotypic hippocampal neurons increased spine density while decreasing CREB function by expression of a dominant negative CREB or a CREBtargeted shRNA inhibited spine formation (Impey et al., 2010). Consistent with this, increasing CREB function in hippocampal CA1 principal neurons restored the decrease in spine density and improved spatial memory in a mouse model of Alzheimer's disease (Yiu et al., 2011). Recent work has shown that CREB-induced excitability of LA neurons may be a potential mechanism for preferential recruitment of these neurons to the fear memory trace (Zhou et al., 2009).

Based on the previous work, we hypothesized that CREB's role in allocation of tone fear memory may be caused by its effect on regulation of spine density of LA neurons. The LA receives sensory (both tone and footshock) information directly from auditory cortex and thalamus (LeDoux et al., 1990; Campeau and Davis, 1995) and is thought to be the critical site for convergence of US and CS inputs in auditory fear conditioning experiments. Therefore, neurons with more dendritic spines may be preferentially activated by the CS and US convergence and become part of the memory trace.

Here, we observed that changes in CREB function alone were sufficient to change dendritic spine density, and that neurons with increased CREB function showed higher dendritic spine density. Furthermore we observed that neurons with higher CREB function were preferentially allocated to the memory trace. Because synapses and spines play a key role in neuronal information processing, changes in dendritic spine density or morphology of a neuron may affect synaptic function and local circuit organization. Along with other factors, such as changes in neuronal excitability (Zhou et al., 2009), changes in the synapse and spine number and morphology may influence neuronal spiking activity and play important roles in neuronal memory allocation.

\section{ACKNOWLEDGMENTS}

We thank Mika Yamamoto, Russell Braybon and Antonietta (Toni) Decristofaro for excellent technical assistance and members of the Josselyn/Frankland laboratory for their helpful suggestions throughout this project. This work was supported by grants from the Canadian Institutes of Health Research (CIHR; MOP-74650), EJLB Foundation and the Alzheimer's Society of Canada to Sheena A. Josselyn and CIHR (MOP- 86762) to Paul W. Frankland. Derya Sargin and Adelaide P. Yiu received support from the Alzheimer's Society, Adelaide P. Yiu received support from Restracomp Fellowships (Hospital for Sick Children). We thank Christina Cole for surgical excellence and Matthew Florczynski for technical help.

\section{REFERENCES}

Aguado, F., Diaz-Ruiz, C., Parlato, R., Martinez, A., Carmona, M. A., Bleckmann, S., et al. (2009). The CREB/CREM transcription factors negatively regulate early synaptogenesis and spontaneous network activity. J. Neurosci. 29, 328-333. doi: 10.1523/JNEUROSCI.525208.2009 
Altarejos, J. Y., and Montminy, M. (2011). CREB and the CRTC co-activators: sensors for hormonal and metabolic signals. Nat. Rev. Mol. Cell Biol. 12, 141-151. doi: $10.1038 / \mathrm{nrm} 3072$

Bailey, C. H., Bartsch, D., and Kandel, E. R. (1996). Toward a molecular definition of long-term memory storage. Proc. Natl. Acad. Sci. U.S.A. 93, 13445-13452. doi: 10.1073/pnas.93.24.13445

Bailey, C. H., and Kandel, E. R. (1993). Structural changes accompanying memory storage. Annu. Rev. Physiol. 55, 397-426. doi: 10.1146/annurev.ph.55.030193.002145

Balschun, D., Wolfer, D. P., Gass, P., Mantamadiotis, T., Welzl, H., Schütz, G., et al. (2003). Does cAMP response element-binding protein have a pivotal role in hippocampal synaptic plasticity and hippocampus-dependent memory? J. Neurosci. 23, 6304-6314.

Barrot, M., Olivier, J. D. A., Perrotti, L. I., DiLeone, R. J., Berton, O., Eisch, A. J., et al. (2002). CREB activity in the nucleus accumbens shell controls gating of behavioral responses to emotional stimuli. Proc. Natl. Acad. Sci. U.S.A. 99, 11435-11440. doi: 10.1073/pnas.172091899

Bartsch, D., Casadio, A., Karl, K. A., Serodio, P., and Kandel, E. R. (1998). CREB1 encodes a nuclear activator, a repressor, and a cytoplasmic modulator that form a regulatory unit critical for long-term facilitation. Cell 95, 211-223. doi: 10.1016/S0092-8674(00)81752-3

Bartsch, D., Ghirardi, M., Skehel, P. A., Karl, K. A., Herder, S. P., Chen, M., et al. (1995). Aplysia CREB2 represses long-term facilitation: Relief of repression converts transient facilitation into long-term functional and structural change. Cell 83, 979-992. doi: 10.1016/0092-8674(95)90213-9

Bourtchuladze, R., Frenguelli, B., Blendy, J., Cioffi, D., Schütz, G., and Silva, A. J. (1994). Deficient long-term memory in mice with a targeted mutation of the cAMP-responsive element-binding protein. Cell 79, 59-68. doi: 10.1016/00928674(94)90400-6

Cajal, S. R. Y. (1995). Histology of the Nervous System of Man and Vertebrates. New York, NY: Oxford University Press.

Campeau, S., and Davis, M. (1995). Involvement of the central nucleus and basolateral complex of the amygdala in fear conditioning measured with fear-potentiated startle in rats trained concurrently with auditory and visual conditioned stimuli. J. Neurosci. 15, 2301-2311.

Carlezon, W. A., and Neve, R. L. (2003). Viral-mediated gene transfer to study the behavioral correlates of CREB function in the nucleus accumbens of rats. Methods Mol. Med. 79, 331-350.

Cole, C. J., Mercaldo, V., Restivo, L., Yiu, A. P., Sekeres, M. J., Han, J.-H., et al. (2012). MEF2 negatively regulates learning-induced structural plasticity and memory formation. Nat. Neurosci. 15, 1255-1264. doi: 10.1038/ nn.3189

Dash, P. K., Hochner, B., and Kandel, E. R. (1990). Injection of the cAMPresponsive element into the nucleus of Aplysia sensory neurons blocks longterm facilitation. Nature 345, 718-721. doi: 10.1038/345718a0

Davis, M. (1992). The role of the amygdala in fear and anxiety. Annu. Rev. Neurosci. 15, 353-375. doi: 10.1146/annurev.ne.15.030192.002033

Farb, C., Aoki, C., Milner, T., Kaneko, T., and LeDoux, J. (1992). Glutamate immunoreactive terminals in the lateral amygdaloid nucleus: a possible substrate for emotional memory. Brain Res. 593, 145-158. doi: 10.1016/00068993(92)91303-V

Feldman, M. L., and Dowd, C. (1975). Loss of dendritic spines in aging cerebral cortex. Anat. Embryol. (Berl.) 148, 279-301. doi: 10.1007/BF00319848

Gass, P., Wolfer, D. P., Balschun, D., Rudolph, D., Frey, U., Lipp, H. P., et al. (1998). Deficits in memory tasks of mice with CREB mutations depend on gene dosage. Learn. Mem. 5, 274-288.

Gruart, A., Benito, E., Delgado-García, J. M., and Barco, A. (2012). Enhanced cAMP response element-binding protein activity increases neuronal excitability, hippocampal long-term potentiation, and classical eyeblink conditioning in alert behaving mice. J. Neurosci. 32, 17431-17441. doi: 10.1523/JNEUROSCI.433912.2012

Guzowski, J. F., and McGaugh, J. L. (1997). Antisense oligodeoxynucleotidemediated disruption of hippocampal cAMP response element binding protein levels impairs consolidation of memory for water maze training. Proc. Natl. Acad. Sci. U.S.A. 94, 2693-2698. doi: 10.1073/pnas.94. 6.2693

Han, J.-H., Kushner, S. A., Yiu, A. P., Cole, C. J., Matynia, A., Brown, R. A., et al. (2007). Neuronal competition and selection during memory formation. Science 316, 457-460. doi: 10.1126/science. 1139438
Han, J.-H., Kushner, S. A., Yiu, A. P., Hsiang, H.-L., Buch, T., Waisman, A., et al. (2009). Selective erasure of a fear memory. Science 323, 1492-1496. doi: 10.1126/science.1164139

Han, J.-H., Yiu, A. P., Cole, C. J., Hsiang, H.-L., Neve, R. L., and Josselyn, S. A. (2008). Increasing CREB in the auditory thalamus enhances memory and generalization of auditory conditioned fear. Learn. Mem. 15, 443-453. doi: 10.1101/lm.993608

Harris, K. M., Jensen, F. E., and Tsao, B. (1992). Three-dimensional structure of dendritic spines and synapses in rat hippocampus (CA1) at postnatal day 15 and adult ages: implications for the maturation of synaptic physiology and longterm potentiation. J. Neurosci. 12, 2685-2705.

Harris, K. M., and Stevens, J. K. (1988). Dendritic spines of rat cerebellar Purkinje cells: serial electron microscopy with reference to their biophysical characteristics. J. Neurosci. 8, 4455-4469.

Harris, K. M., and Stevens, J. K. (1989). Dendritic spines of CA 1 pyramidal cells in the rat hippocampus: serial electron microscopy with reference to their biophysical characteristics. J. Neurosci. 9, 2982-2997.

Harum, K. H., Alemi, L., and Johnston, M. V. (2001). Cognitive impairment in Coffin-Lowry syndrome correlates with reduced RSK2 activation. Neurology 56, 207-214. doi: 10.1212/WNL.56.2.207

Horner, C. H., and Arbuthnott, E. (1991). Methods of estimation of spine densityare spines evenly distributed throughout the dendritic field? J. Anat. 177, 179-184.

Impey, S., Davare, M., Lesiak, A., Fortin, D., Ando, H., Varlamova, O., et al. (2010). An activity-induced microRNA controls dendritic spine formation by regulating Racl-PAK signaling. Mol. Cell Neurosci. 43, 146-156. doi: 10.1016/j.mcn.2009.10.005

Josselyn, S. A., and Nguyen, P. V. (2005). CREB, synapses and memory disorders: past progress and future challenges. Curr. Drug Targets CNS Neurol. Disord. 4, 481-497. doi: 10.2174/156800705774322058

Josselyn, S. A., Shi, C., Carlezon, W. A., Neve, R. L., Nestler, E. J., and Davis, M. (2001). Long-term memory is facilitated by cAMP response element-binding protein overexpression in the amygdala. J. Neurosci. 21, 2404-2412.

Kaang, B. K., Kandel, E. R., and Grant, S. G. (1993). Activation of cAMP-responsive genes by stimuli that produce long-term facilitation in Aplysia sensory neurons. Neuron 10, 427-435. doi: 10.1016/0896-6273(93)90331-K

Kauffman, A. L., Ashraf, J. M., Corces-Zimmerman, M. R., Landis, J. N., and Murphy, C. T. (2010). Insulin signaling and dietary restriction differentially influence the decline of learning and memory with age. PLoS Biol. 8:e1000372e1000372. doi: 10.1371/journal.pbio.1000372

Kida, S., Josselyn, S. A., Peña de Ortiz, S., Kogan, J. H., Chevere, I., Masushige, S., et al. (2002). CREB required for the stability of new and reactivated fear memories. Nat. Neurosci. 5, 348-355. doi: 10.1038/nn819

Lau, H. L., Timbers, T. A., Mahmoud, R., and Rankin, C. H. (2013). Genetic dissection of memory for associative and non-associative learning in Caenorhabditis elegans. Genes Brain Behav.12, 210-223. doi: 10.1111/j.1601-183X.2012. 00863.x

LeDoux, J. E., Cicchetti, P., Xagoraris, A., and Romanski, L. M. (1990). The lateral amygdaloid nucleus: sensory interface of the amygdala in fear conditioning. J. Neurosci.10, 1062-1069.

Lonze, B. E., Riccio, A., Cohen, S., and Ginty, D. D. (2002). Apoptosis, axonal growth defects, and degeneration of peripheral neurons in mice lacking CREB. Neuron 34, 15-15. doi: 10.1016/S0896-6273(02)00686-4

Marie, H., Morishita, W., Yu, X., Calakos, N., and Malenka, R. C. (2005). Generation of silent synapses by acute in vivo expression of CaMKIV and CREB. Neuron 45, 12-12. doi: 10.1016/j.neuron.2005.01.039

Matsuzaki, M., Ellis-Davies, G. C., Nemoto, T., Miyashita, Y., Iino, M., and Kasai, H. H. (2001). Dendritic spine geometry is critical for AMPA receptor expression in hippocampal CA1 pyramidal neurons. Nat. Neurosci. 4, 1086-1092. doi: $10.1038 / \mathrm{nn} 736$

Matsuzaki, M., Honkura, N., Ellis-Davies, G. C. R., and Kasai, H. (2004). Structural basis of long-term potentiation in single dendritic spines. Nature 429, 761-766. doi: $10.1038 /$ nature 02617

Mayr, B., and Montminy, M. (2001). Transcriptional regulation by the phosphorylation-dependent factor CREB. Nat. Rev. Mol. Cell Biol. 2, 599-609. doi: $10.1038 / 35085068$

McDonald, A. J. (1984). Neuronal organization of the lateral and basolateral amygdaloid nuclei of the rat. J. Comp. Neurol. 222, 589-606. doi: $10.1002 /$ cne. 902220410 
McDonald, A. J. (1992). "Cell types and intrinsic connections of the amygdala," in The Amygdala: Neurobiological Aspects of Emotion, Memory, and Mental Dysfunction, ed J. P. Aggleton (New York, NY: Wiley-Liss), 69-76.

Murphy, D. D., and Segal, M. (1997). Morphological plasticity of dendritic spines in central neurons is mediated by activation of cAMP response element binding protein. Proc. Natl. Acad. Sci. U.S.A. 94, 1482-1487. doi: 10.1073/pnas.94.4.1482

Pandey, S. C., Roy, A., and Zhang, H. (2003). The decreased phosphorylation of cyclic adenosine monophosphate (cAMP) response element binding (CREB) protein in the central amygdala acts as a molecular substrate for anxiety related to ethanol withdrawal in rats. Alcohol Clin. Exp. Res. 27, 396-409. doi: 10.1097/01.ALC.0000056616.81971.49

Pandey, S. C., Zhang, H., Roy, A., and Xu, T. (2005). Deficits in amygdaloid cAMP-responsive element-binding protein signaling play a role in genetic predisposition to anxiety and alcoholism. J. Clin. Invest. 115, 2762-2773. doi: 10.1172/JCI24381

Paxinos, G., and Franklin, K. B. J. (2001). The Mouse Brain in Stereotaxic Coordinates. San Diego, Academic Press.

Perazzona, B., Isabel, G., Preat, T., and Davis, R. L. (2004). The role of cAMP response element-binding protein in Drosophila long-term memory. J. Neurosci. 24, 8823-8828. doi: 10.1523/JNEUROSCI.4542-03.2004

Peters, A., and Kaiserman-Abramof, I. R. (1970). The small pyramidal neuron of the rat cerebral cortex. The perikaryon, dendrites and spines. Dev. Dyn. 127, 321-355.

Pittenger, C., Huang, Y. Y., Paletzki, R. F., Bourtchouladze, R., Scanlin, H., Vronskaya, S., et al. (2002). Reversible Inhibition of CREB/ATF Transcription Factors in Region CAl of the Dorsal Hippocampus Disrupts Hippocampus-Dependent Spatial Memory. Neuron 34, 16-16. doi: 10.1016/S0896-6273(02)00684-0

Rexach, J. E., Clark, P. M., Mason, D. E., Neve, R. L., Peters, E. C., and Hsieh-Wilson, L. C. (2012). Dynamic O-GlcNAc modification regulates CREB-mediated gene expression and memory formation. Nat. Chem. Biol. 8, 253-261. doi: 10.1038/nchembio.770

Russo, S. J., Wilkinson, M. B., Mazei-Robison, M. S., Dietz, D. M., Maze, I., Krishnan, V., et al. (2009). Nuclear factor kappa B signaling regulates neuronal morphology and cocaine reward. J. Neurosci. 29, 3529-3537. doi: 10.1523/JNEUROSCI.6173-08.2009

Sah, P., Faber, E. S., Lopez De Armentia, M., and Power, J. (2003). The amygdaloid complex: anatomy and physiology. Physiol. Rev. 83, 803-834.

Silva, A. J., Kogan, J. H., Frankland, P. W., and Kida, S. (1998). CREB and memory. Annu. Rev. Neurosci. 21, 127-148. doi: 10.1146/annurev.neuro.21.1.127

Silva, A. J., Simpson, E. M., Takahashi, J. S., Lipp, H-P., Nakanishi, S., Wehner, J. M., et al. (1997). Mutant mice and neuroscience: recommendations concerning genetic background. Neuron 19, 755-759. doi: 10.1016/S0896-6273(00)80958-7

Suzuki, S., Zhou, H., Neumaier, J. F., and Pham, T. A. (2007). Opposing functions of CREB and MKK1 synergistically regulate the geometry of dendritic spines in visual cortex. J. Comp. Neurol. 503, 605-617. doi: 10.1002/cne.21424

Valverde, O., Mantamadiotis, T., Torrecilla, M., Ugedo, L., Pineda, J., Bleckmann, S., et al. (2004). Modulation of anxiety-like behavior and morphine dependence in CREB-deficient mice. Biol. Psychiatry 29, 1122-1133. doi: 10.1038/sj.npp.1300416
Vetere, G., Restivo, L., Cole, C. J., Ross, P. J., Ammassari-Teule, M., Josselyn, S. A., et al. (2011). Spine growth in the anterior cingulate cortex is necessary for the consolidation of contextual fear memory. Proc. Natl. Acad. Sci. U.S.A. 108, 8456-8460. doi: 10.1073/pnas.1016275108

Viosca, J., Lopez de Armentia, M., Jancic, D., and Barco, A. (2009). Enhanced CREB-dependent gene expression increases the excitability of neurons in the basal amygdala and primes the consolidation of contextual and cued fear memory. Learn. Mem. 16, 193-197. doi: 10.1101/lm.1254209

Wayman, G. A., Impey, S., Marks, D., Saneyoshi, T., Grant, W. F., Derkach, V., et al. (2006). Activity-dependent dendritic arborization mediated by CaM-kinase I activation and enhanced CREB-dependent transcription of Wnt-2. Neuron 50, 897-909. doi: 10.1016/j.neuron.2006.05.008

Won, J., and Silva, A. J. (2008). Molecular and cellular mechanisms of memory allocation in neuronetworks. Neurobiol. Learn. Mem. 89, 285-292. doi: 10.1016/j.nlm.2007.08.017

Yin, J. C., Del Vecchio, M., Zhou, H., and Tully, T. (1995). CREB as a memory modulator: induced expression of a dCREB2 activator isoform enhances long-term memory in drosophila. Cell 81, 9-9. doi: 10.1016/0092-8674(95) 90375-5

Yin, J. C., Wallach, J. S., Del Vecchio, M., Wilder, E. L., Zhou, H., Quinn, W. G., et al. (1994). Induction of a dominant negative CREB transgene specifically blocks long-term memory in Drosophila. Cell 79, 49-58. doi: 10.1016/00928674(94)90399-9

Yiu, A. P., Rashid, A. J., and Josselyn, S. A. (2011). Increasing CREB function in the CA1 region of dorsal hippocampus rescues the spatial memory deficits in a mouse model of Alzheimer's disease. Neuropsychopharmacology 36, 2169-2186. doi: 10.1038/npp.2011.107

Zhou, Y., Won, J., Karlsson, M. G., Zhou, M., Rogerson, T., Balaji, J., et al. (2009). CREB regulates excitability and the allocation of memory to subsets of neurons in the amygdala. Nat. Neurosci.12, 1438-1443. doi: 10.1038/nn.2405

Conflict of Interest Statement: The authors declare that the research was conducted in the absence of any commercial or financial relationships that could be construed as a potential conflict of interest.

Received: 11 September 2013; paper pending published: 06 November 2013; accepted: 05 December 2013; published online: 20 December 2013.

Citation: Sargin D, Mercaldo V, Yiu AP, Higgs G, Han J-H, Frankland PW and Josselyn SA (2013) CREB regulates spine density of lateral amygdala neurons: implications for memory allocation. Front. Behav. Neurosci. 7:209. doi: 10.3389/fnbeh. 2013.00209

This article was submitted to the journal Frontiers in Behavioral Neuroscience. Copyright (c) 2013 Sargin, Mercaldo, Yiu, Higgs, Han, Frankland and Josselyn. This is an open-access article distributed under the terms of the Creative Commons Attribution License (CC BY). The use, distribution or reproduction in other forums is permitted, provided the original author(s) or licensor are credited and that the original publication in this journal is cited, in accordance with accepted academic practice. No use, distribution or reproduction is permitted which does not comply with these terms. 